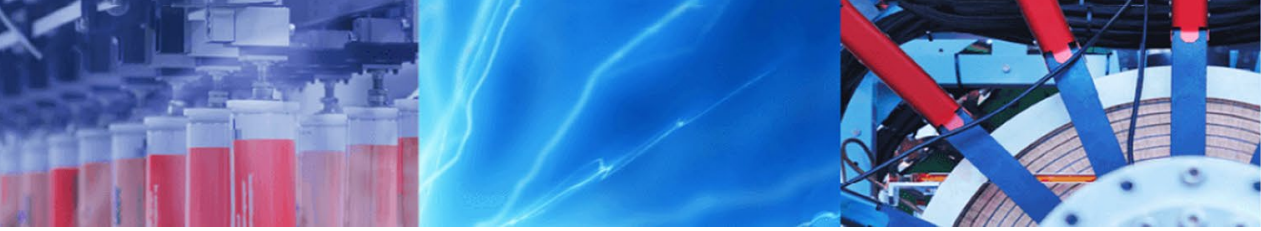

Research Article

\title{
Application of production data-driven diagnostics workflow for water shut-off candidate selection in tight carbonate field
}

\author{
Seyedeh Hosna Talebian ${ }^{1}\left[\right.$ ] Ali Beglari ${ }^{1}$
}

Received: 13 August 2019 / Accepted: 13 November 2019 / Published online: 28 November 2019

(c) Springer Nature Switzerland AG 2019

\begin{abstract}
The newly developed tight carbonates impose many challenges during the early production stage due to the reservoir rock and fluid heterogeneities which has limited the utilization of simulation model as the main way of data integration and performance prediction. Therefore, the surveillance data-driven analytics coupled with petrophysical and stress state properties become of interest to reduce uncertainties involved in selecting reliable improved oil recovery candidates in these reservoirs. This paper presents a workflow based on production data for water shut-off (WSO) candidate selection. The WSO candidates were recognized based on heterogeneity index, decline curve analysis, water oil ratio and the effect of excess water production on the well ultimate recovery. The mechanism and source of produced water was diagnosed based on Chan plot and Stiff diagram through the presented screening.
\end{abstract}

Keywords Production data diagnostics · Carbonate reservoir · Heterogeneity index · Water shut-off

\section{Introduction}

As a result of the reduction trend in exploration of new major carbonate fields and a decline in production of conventional reserves categorized as easy oil, development of deep tight carbonates with more complexities in reservoir rock and fluid behavior have become of interest for exploration and development companies in recent years [14]. The newly developed tight carbonate fields impose many challenges during the early production stage due to the reservoir heterogeneities, fluid behavior complexities and the asphaltene deposition-induced problems that make the sub-surface understanding and availability of data for further routine analysis limited [2]. The use of simulation models as the main way of integration is also limited. Therefore, surveillance data-driven diagnostics integrated with petrophysical data and field observations become of interest to reduce uncertainties and risks involved in selecting reliable improved oil recovery (IOR) candidates.
The main types of water problems in oil field, the water shut-off methods in wellbore or reservoir and a production data driven screening algorithm to select water shutoff candidate are discussed in this paper. The proposed candidate selection workflow has been applied in a deep tight carbonate reservoir that is facing unwanted water production issue in the early stage of field development. The workflow has been applied in oil field manager (OFM) platform for the purpose of production data integration.

\subsection{Nature of water problems}

Figure 1 is a schematic overview of the 10 basic water problem types from easy to solve to the most difficult to solve [7]. The origin of the water production needs to be defined before any decision for downhole water control process [3].

In newly developed reservoirs where water oil contact (WOC) is not expected to be observed by production wells,

Seyedeh Hosna Talebian, hsn.talebian@gmail.com | ${ }^{1}$ Department of Petroleum Engineering, Sarvak Azar Engineering and Development (SAED), Tehran, Iran. 


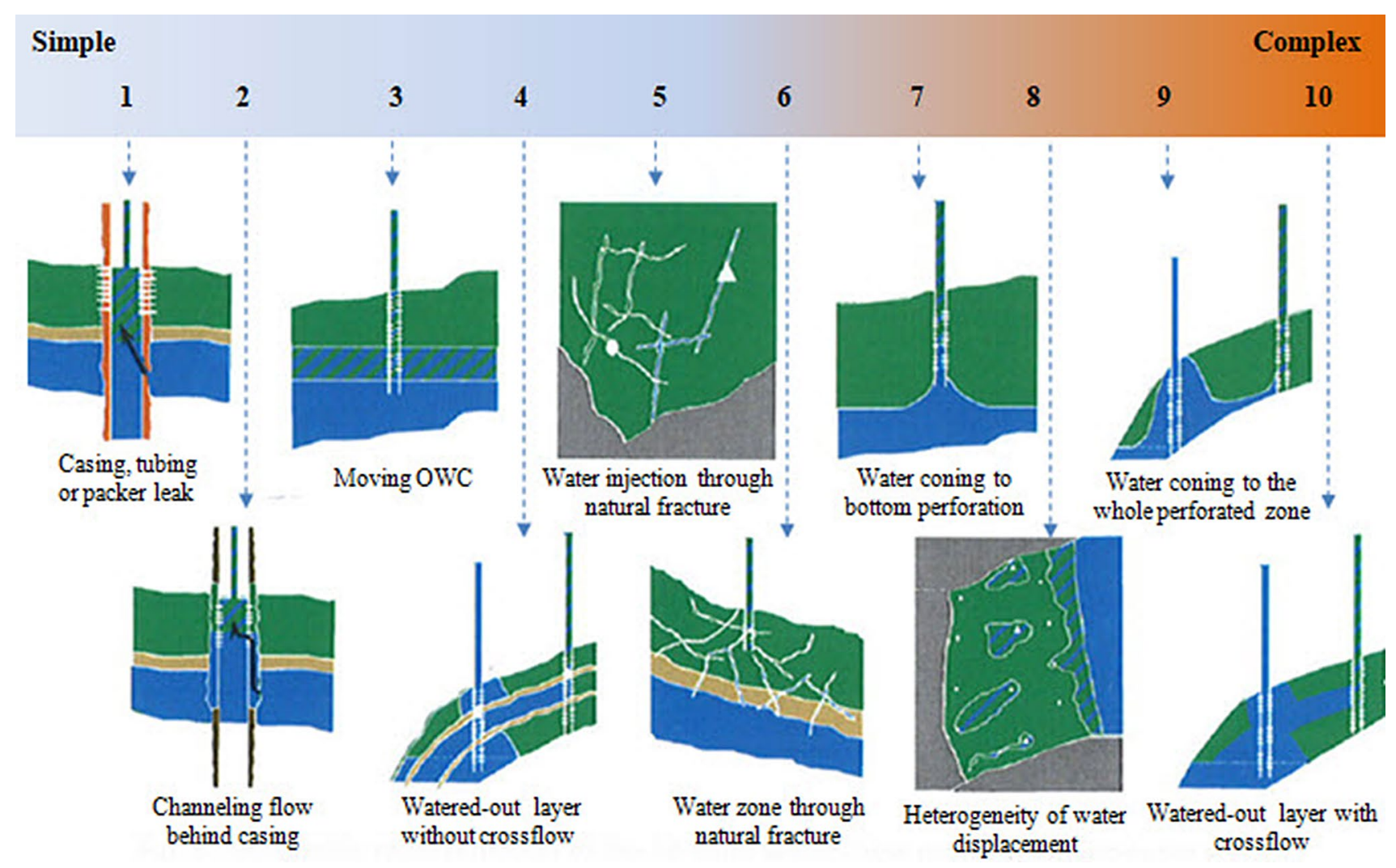

Fig. 1 Schematic representation of the main water-type problems in producer wells [3]

the excess water production can be due to a combination of geology and stress conditions that lead to formation of a localized movable water above the transition zone that is not actually connected to the actual free-water table. This type of water traps, also known as perched-water zones, is formed when saturated conditions above a low permeability layer force water to move vertically through this layer. When moving water encounters resistance due to low permeability, the pressure builds up creating a perched-water head to filtrate the water through the tight layer [8].

\subsection{Water shut-off methods}

Produced water is defined as water co-produced with crude oil during production operations and consists of formation water or flood water previously injected into the formation for pressure maintenance purpose. Produced water is typically hot and corrosive, containing suspended solids and oil from the formation and production operations, salts and chemicals injected at various points in the production system [15]. The residues of chemicals injected to control asphaltene, corrosion and emulsion in soured and asphaltenic oil field are the source of contaminants in produced water.
Handling of water on the surface is costly and poses potential negative effects on the environment due to discharge to sea or reinjection. The potential negative effect is strongly dependent on the differential in any parameter between the produced water and the receiving environment, whether that environment is an open surface (in case of discharge) or an underground formation (in case of reinjection). The generally preferred hierarchy for environmental management is (1) reduce, (2) re-use/recycle and (3) disposal [6]. Although produced water injection to disposal zones or reinjection into the source oil zone is regarded as the practicable environmental option, compatibility issues, impaired injectivity, reservoir fracture and induced sustaining bacterial activity are the vital issues for many projects [12]. Therefore, shutting off water production down-hole rather than producing with the oil to surface is recommended. The proactive and reactive downhole water shut-off methods are listed in Fig. 2.

In smart completions, the flow control devices can be implemented to manage water cut based on economic limit through well/field life. The inflow control device (ICD) valve can delay and reduce water coning and breakthrough and enable production from multiple zones with different permeability and pressures. However, even though ICDs create additional pressure drop to balance 
Fig. 2 Proactive and reactive water shut-off (WSO) techniques

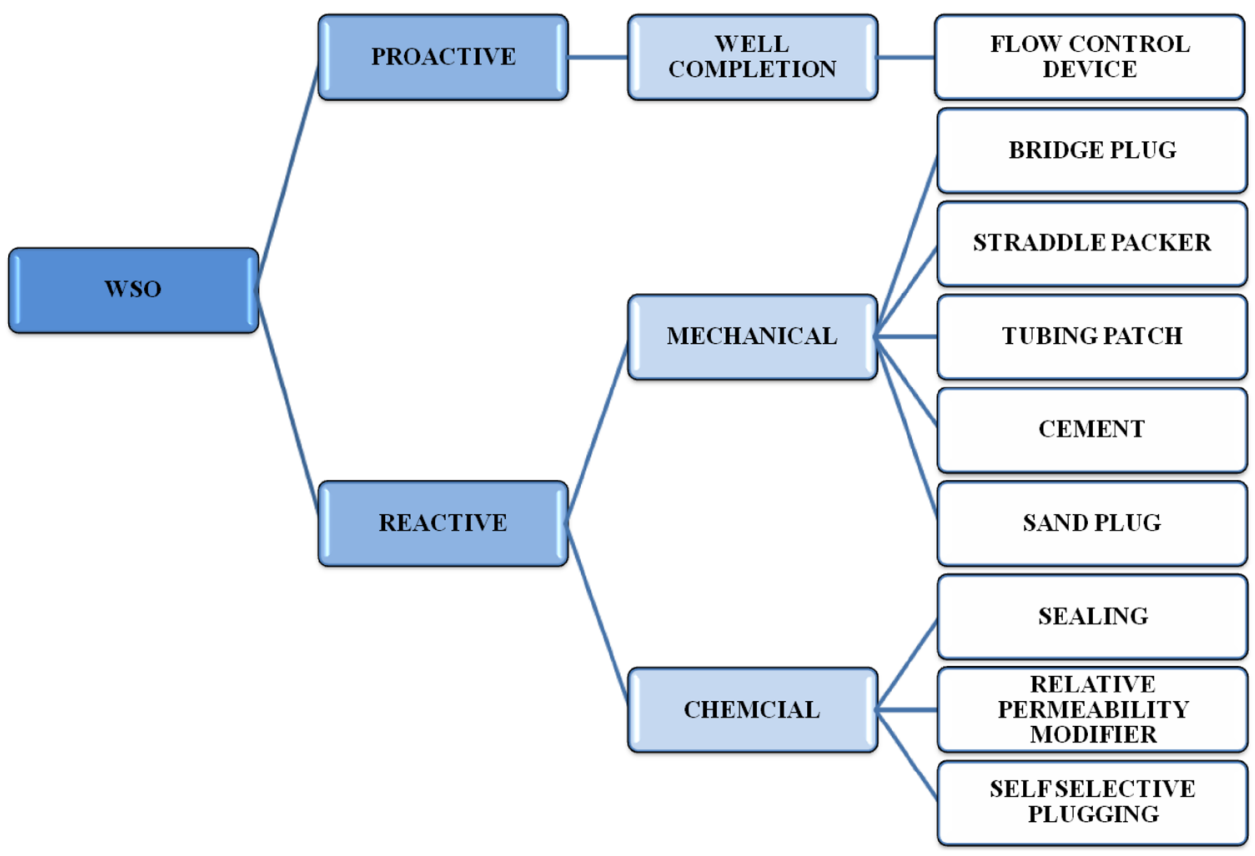

the production flux, but it cannot restrict unwanted effluents once they break through. The autonomous inflow control device (AICD) was introduced to address the ICD limitations. AICD is a proactive solution to long horizontal wells which have a tendency to water/gas out towards the heel of the well by choking back these areas to give more uniform inflow profile along the length of the well [13]. The proactive technologies are self-regulating and autonomous. However, they are more expensive and dependent on the field reservoir management decisions that make their application limited. The mechanical water shut-off techniques are more straight-forward. In case a zone at the bottom of the perforated interval has watered out, the well can simply be plugged back. However, where the reservoir is layered or where there is commingle production from more than one reservoir, there may be a water producing zone higher in well than zones producing oil. In this case, it has been conventional to shut-off water production by a cement squeeze, or setting straddle packer or bridge plug across the watered out zone. Moreover, these methods introduce a limitation to tubing which is a critical consideration for monobore completions designed for through-tubing well intervention. Also, almost all mechanical water control technologies require at least the production logging tool (PLT) to identify the source of water and in mature wells, it is difficult to justify running logging tools. Therefore, chemical treatments offers rather cost-effective alternatives such as reservoir gel treatments, downhole separation and relative permeability modifier. The chromium crosslinked polymer gels presented advantage over cement and other mechanical devices due to its flexibility of application, good control of setting time, ease to clean and operation cost according to field trial [4]. The self-selective plugging is based on concept of employing a liquid plugging which in a given period of time is capable of solidifying in the presence of water or brine under prevailed wellbore pressure and temperature. The relative permeability modifier technology is essentially polymer systems which selectively restrict in-flow of water to the well, whilst allowing essentially unrestricted flow of oil. They offer the considerable advantage that they can be unselectively injected into the producing interval rather than having to be placed in the special zone using, for example, coil tubing.

\section{Diagnostic analysis workflow}

Although different water control efforts have been performed for supporting water production, the mechanisms of excessive water production were not clearly understood or confirmed. Knowing the specific water problem is essential to treating it. The process of candidate selection before execution and to define different types of excessive water production problem is an important subject to investigate. The classic main problems are listed as water coning, multilayer channeling and near wellbore problems. In reality, the problem could be the combination of several mechanisms taking place over the period of time and compounding with one another. Figure 3 is a summary of well-based excess water sources and the recommended solution for each type [1]. Well integrity studies that contain both the completion-related problems such casing leak and cement-casing or cement-formation 


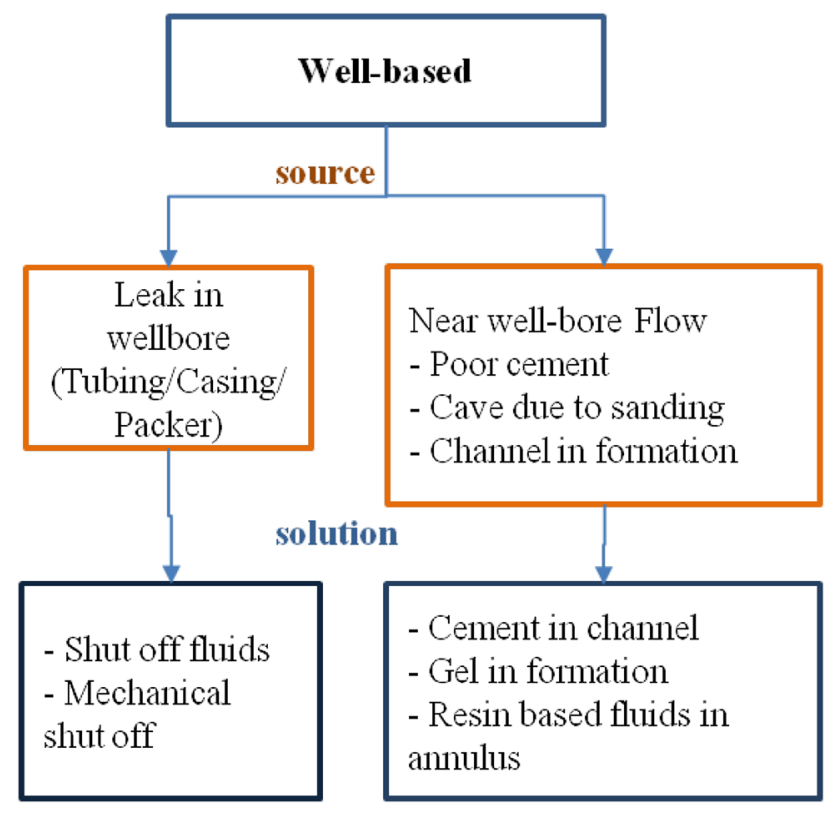

Fig. 3 Wellbore-based water source and solution bonds need to be performed to obtain a holistic solution approach for well-based undesired water production.

Figure 4 is a summary of reservoir-based water sources and the recommended solution techniques based on field applications [4]. In case of oil water contact (OWC) move up in a lower vertical permeability formation, bridge plug and cement plug is the solution to abandon perforations from the bottom. When OWC rises up near perforations in a formation with relatively high vertical permeability, coning occurs. Producing at the conning rate, a rate at which oil can be produced without coning is often too low to be economic. Placing a layer of gel above the OWC can rarely stop coning. Lateral drainholes near the top of formation with a great distance from the OWC can be a good alternative solution. Production of undesired water through fissured network can occur in naturally fractured and faulted systems. The fractures may be treated with a flowing gel near producer. However, the fracture volume is difficult to determine and it may also shutoff the oil-producing fractures. High permeability layer without crossflow is common in multilayer reservoir when a high permeability zone

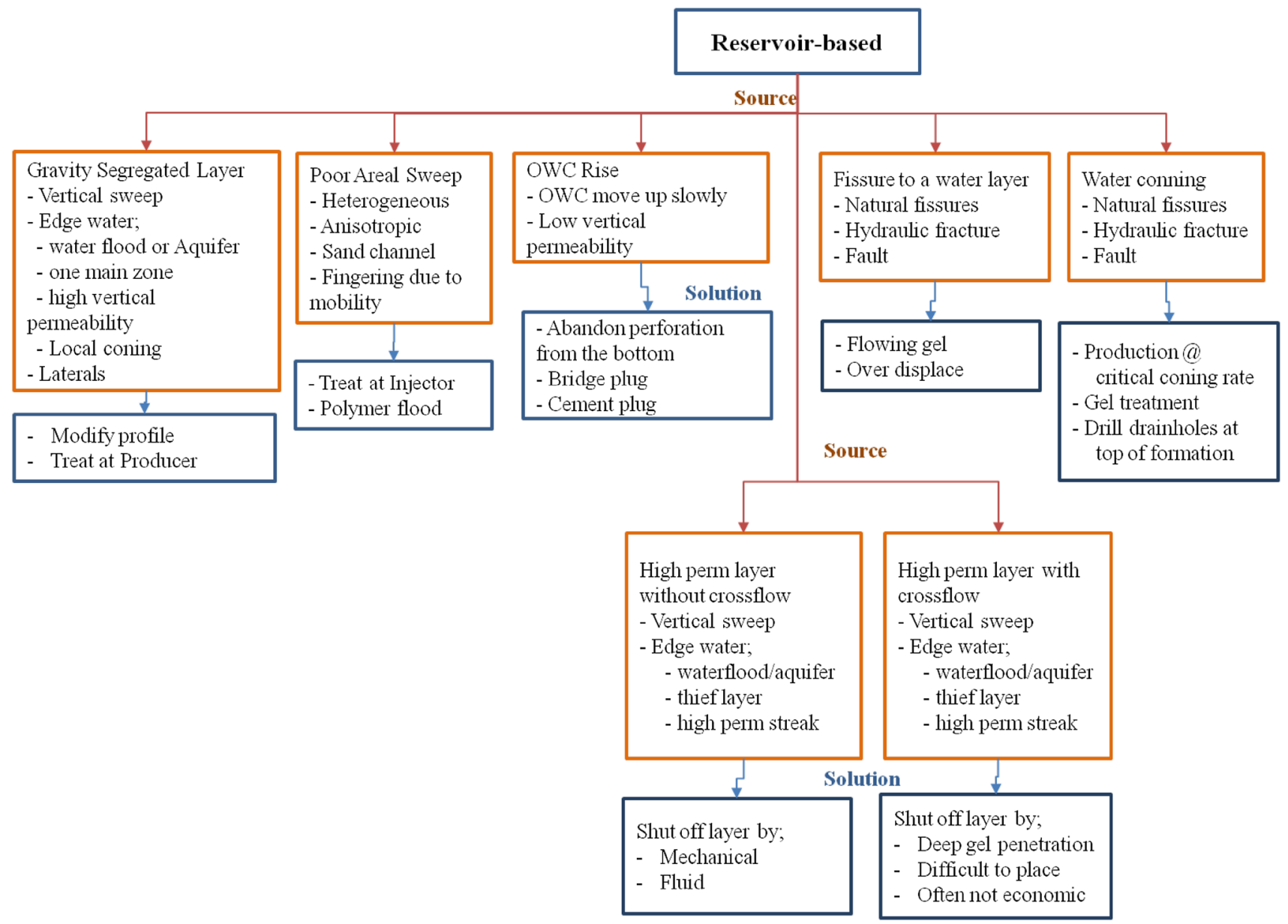

Fig. 4 Reservoir-based water source and solutions 
with flow barrier above and below is watered out from an active aquifer or waterflood injection well. The solution is application of shutoff fluids or mechanical shutoff in either the injector or producer. If the high permeability layer is not isolated by impermeable barriers, there is no barrier to stop the crossflow and attempts to modify production or injection profile near wellbore are doomed to be short-lived and not economical. A solution is to drill a lateral drainhole to access the undrained layers. The waterinjection oriented issues such as gravity segregation or poor areal sweep are potential sources of water problem in waterflood process.

Figure 5 presents the applied workflow that is proposed in the current study to identify the potential WSO candidates or the candidate wells that require more attention for oil production up to their proved reserves.

The heterogeneity index $(\mathrm{HI})$ plot provides a quick screening method to identify the preliminary candidate wells with anomalous behavior (over or under performance of the field average) for further analysis. Most importantly, this plot provides the foundation for the overall structure production approach [9]. In this analysis, well performance is compared at the wellbore level. Individual well performances can be viewed as better or worse than the field average and can be easily compared to each other with scatter plots. The candidates with higher than average field performance water production and lower than the field average oil production from this plot proceed to the next level for reserve estimation. The conventional decline curve analysis (DCA) and the new proposed method $\left(\frac{1}{q_{0}}\right.$ vs. $\left.\frac{N_{p}}{q_{o}}\right)$ to estimate cumulative production is used to predict the candidates' future performance by extrapolating the fitted decline curve function. Where, $q_{o}$ stands for the oil rate and $N_{p}$ is the maximum cumulative oil production from each well. Considering the general field experience that IOR treatments in the wells with higher predicated reserve allow better reservoir management through sustained productivity [10], it is recommended to proceed with the wells with big enough proved recoverable reserve. If the water produced into the wellbore remains below the WOR economic limit through the well life the water is considered good water, as described in workflow. If the filed economic level for handling of water at the surface for the candidate well reaches before the well reaches its expected reserve, the produced water is considered problematic that implies a limit to oil production. Good candidates for water control are

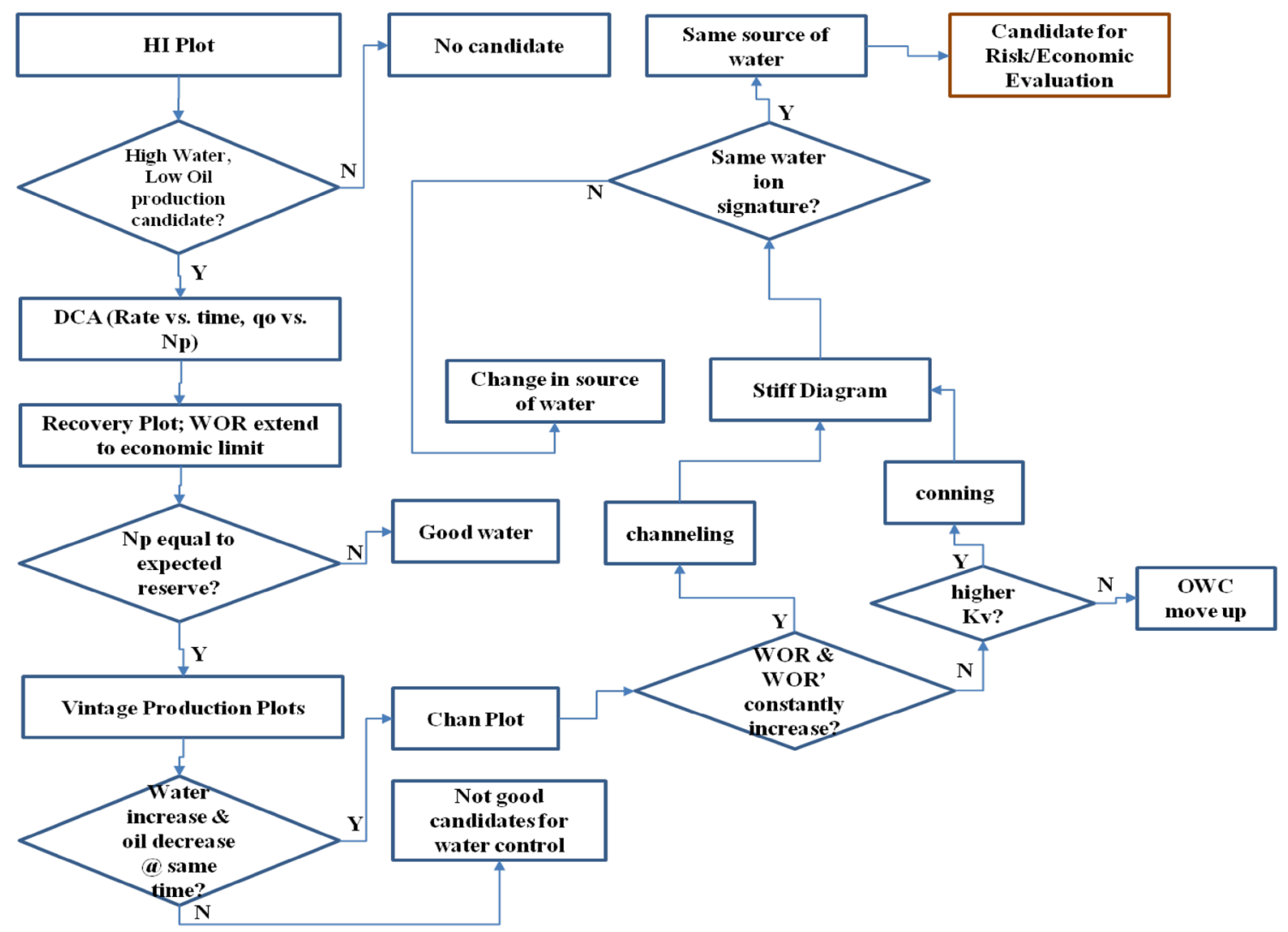

Fig. 5 Candidate selection workflow for water control methods 
expected to show an increase in water production and a decrease in oil production at about the same time. Well WOR and its derivative can be used to differentiate water production mechanisms if coning and channeling. While the water production from the source layer increases very quickly for channeling, it increases relatively slowly for coning. The derivative of WOR (WOR') shows nearly a constant positive slope for channeling and a changing negative slope for coning [5]. Stiff diagram is proposed to compare average major ion composition for candidate well water and study the signature of produced water based on ion diagnosis [11]. if the candidate's source of water is not changing over time, it can be confirmed that the water control methods can be applied to the candidate well for enhancing the well performance.

\section{Application and analysis}

\subsection{Filed example}

The proposed workflow described in Fig. 5 is applied to the production data history of a newly developed tight carbonate field with micro-fracture network system. The single completion, vertical production wells penetrate multiple formation layers and produce from these layers where only one continuous shale barriers separates the two main layers. As can be seen in Fig. 6, three wells (W13, W11, W07) are in Tier 4 of the HI plot, with lower oil production and higher water production compared to the field average. These wells in Tier 4 are subjected to proceed with water shutoff screening analysis. W09 and W12 are in high production Tier 1, with oil and water production above the field average. W02, W03 and W04 wells are in low production Tier 3 , with lower oil and water production than the field average probably due to mechanical issues. Finally, W05 and W06 wells are in Tier 1, which defines the best wells in terms of production history due to higher oil production and lower water production than the field average.

The $\mathrm{HI}$ plot parameters in $\mathrm{y}$ and $\mathrm{x}$ axis are described in Eqs. 1 and 2, respectively.

HSUMW $=\frac{Q_{w} \text { well }}{Q_{w} \text { average of wells }}-1$

$\mathrm{HSUMOIL}=\frac{Q_{o} \text { well }}{Q_{o} \text { average of wells }}-1$

Based on Eqs. 1 and 2, the production wells that fall into negative HSUMOIL and positive HSUMW region during the production history, are selected as the first candidate group. The candidates selected from this plot

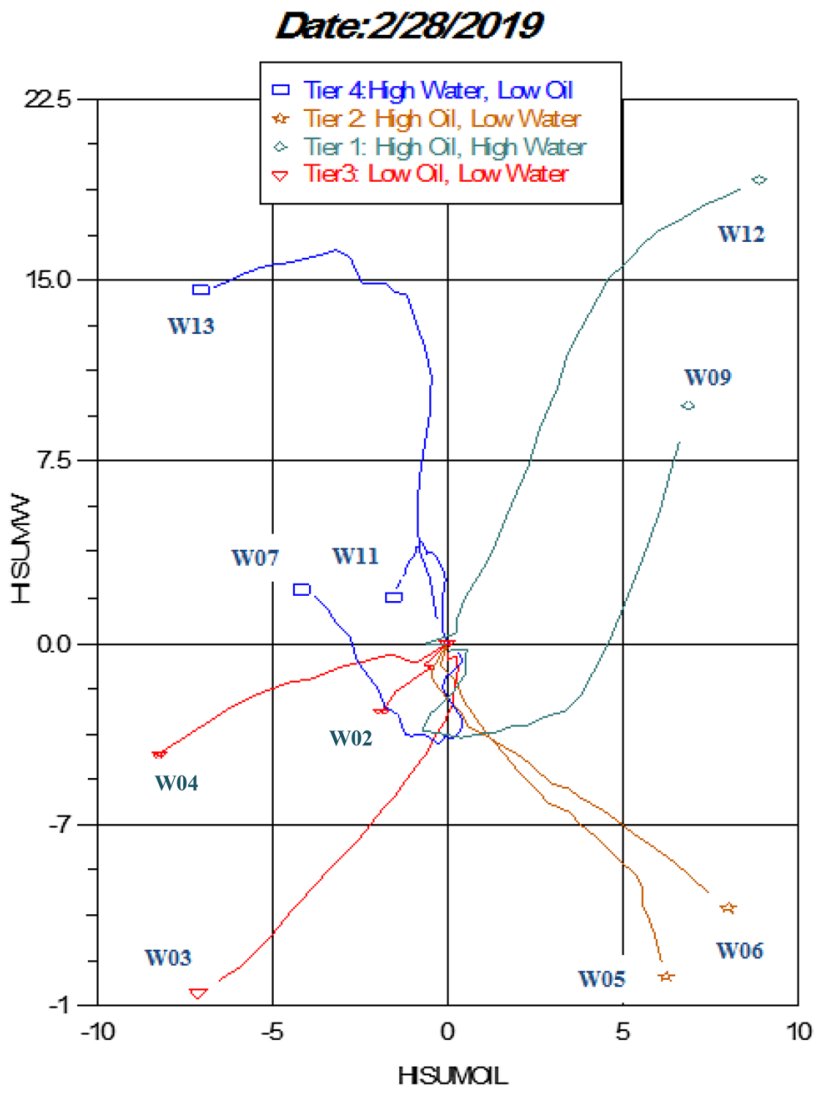

Fig. $6 \mathrm{HI}$ plot of the case study field

are considered to proceed to DCA analysis using two discussed methods. The DCA plots of each candidate are shown in Figs. 7, 8 and 9.

The economic limit for water oil ratio (WOR) for each field can be different depending on parameters such as the water handling cost at surface. Good water is the water produced at a rate below the economic WOR, which is the water that produced oil can pay for it. The economic WOR level in our discussed carbonate field is equal to $30 \%$. The next step is to extrapolate the current WOR to the economic limit amount to identify the cumulative oil produced before reaching that level. The historical WOR and extrapolated plots of candidates are shown in Fig. 10a-c.

From the comparison of the calculated well life-time cumulative oil production $(\mathrm{Np})$ and the cumulative oil production before reaching the WOR economic limit, it can be seen that for candidate W07, the difference between calculated reserve $(\mathrm{Np})$ and the expected production up to water handling limit is high that makes this candidate a potential candidate to proceed to the next level of diagnosis. The WOR extrapolate plot for wells at Tier 2 , which is high oil and low water, is also plotted in Fig. 11, to give a better comprehension of the problem that the candidate wells are facing in the future to produce oil. As can clearly 
Fig. 7 a Rate versus time DCA, b $1 / q_{0}$ versus $\mathrm{Np} / \mathrm{q}_{\mathrm{o}}$ for candidate W13

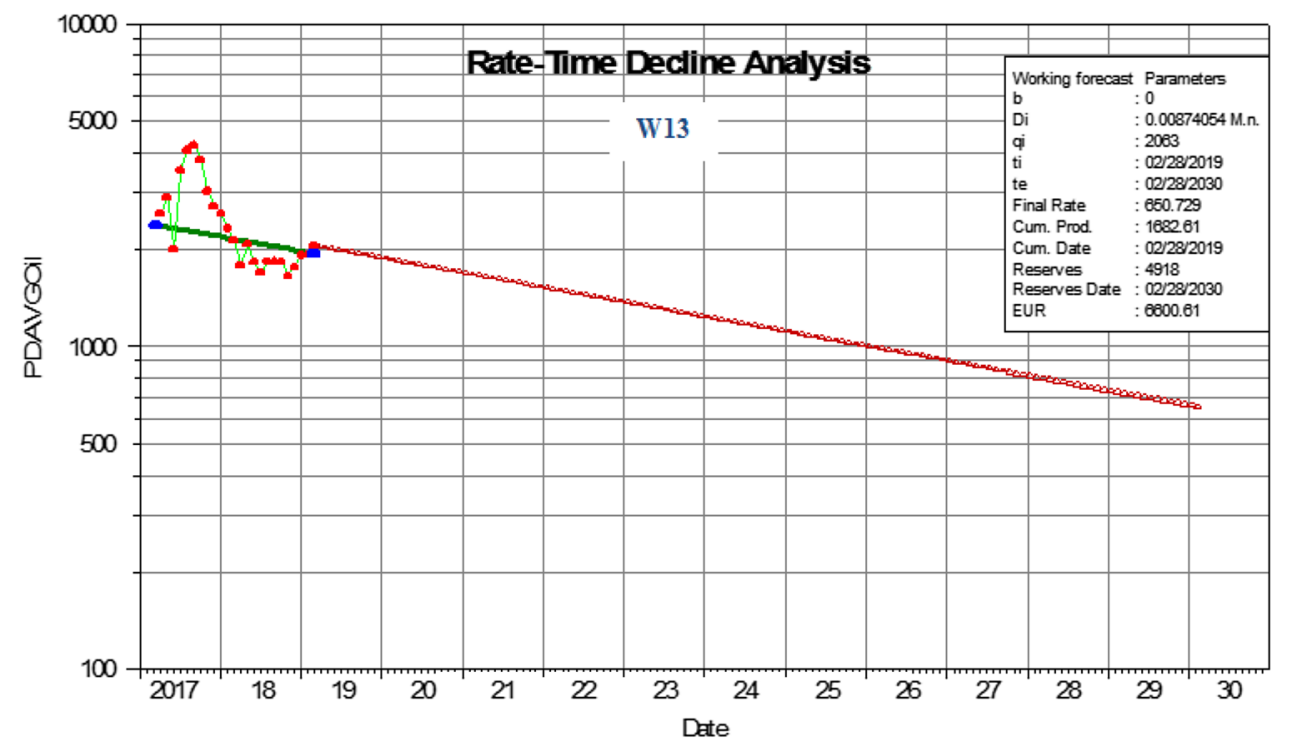

(a)

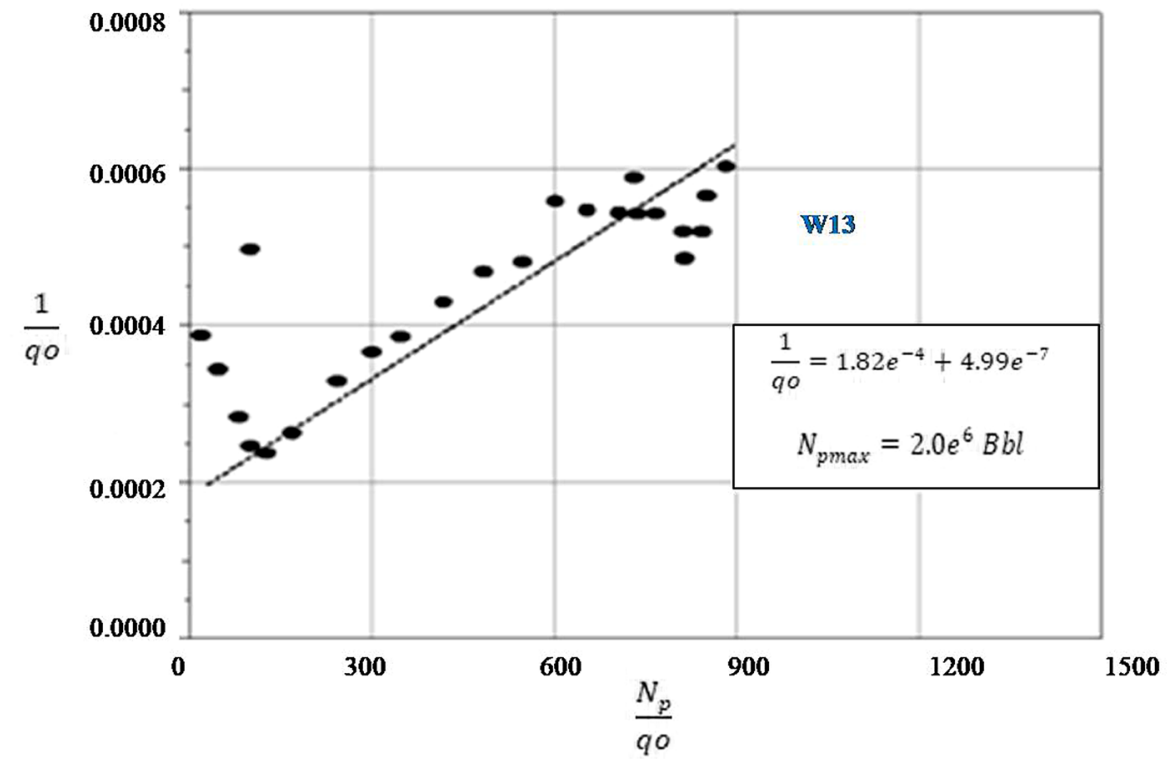

(b) be seen in Fig. 11, the plotted well will not be facing limitation from water production in the well life time.

As the next step of workflow, the vintage plot or production performance history of candidate wells, consisting of monthly oil, monthly water cut percentage and chock size of well during production time, is shown in Fig. 12. According to this plot, the potential water shut-off candidate shows an increase in water production and a decrease in oil production at about the same time, regardless of choke size changes. Based on Fig. 12, W07 shows a constant increase in water cut percentage (wct\%), regardless of the choke size. As can be seen clearly in Fig. 12, the wct\% increased despite the oil rate reduction as the response to the choke size reduction in W07 from 44/64 inch to $40 / 64$ inch.

Although up to this step, W07 candidate is already recognized as the most obvious well for the consideration of water control, Chan plot of all candidates are shown in Fig. 13 to discuss the water production mechanisms. As can be seen in Fig. 13c, W07 shows a water coning situation since WOR derivative vs. time showed a negative slope after about 300 days of production and maintained negative. For W13 and W11 candidates, the WOR derivate is growing positively or the negative slope is not formed yet, respectively that is in contrast with the W07 case. Considering the fact that WOC is not observed in this field yet 
Fig. 8 a Rate versus time DCA, b $1 / q_{o}$ versus $\mathrm{Np} / \mathrm{q}_{\mathrm{o}}$ for candidate W11

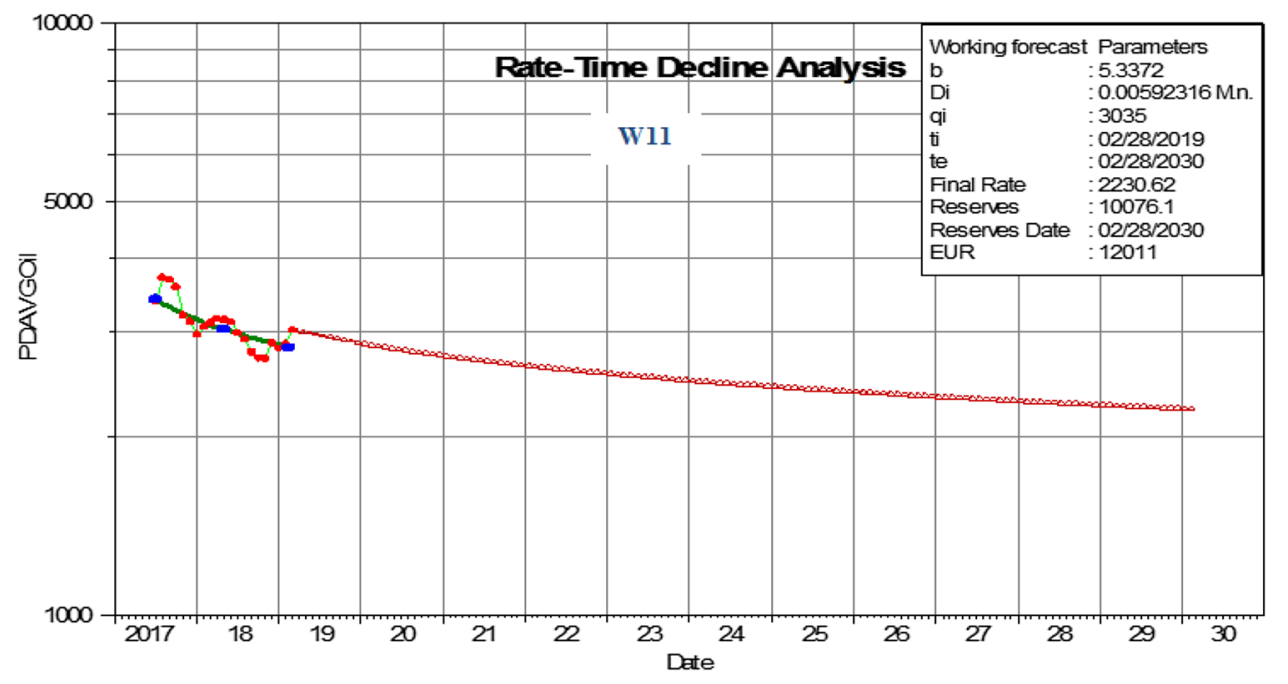

(a)

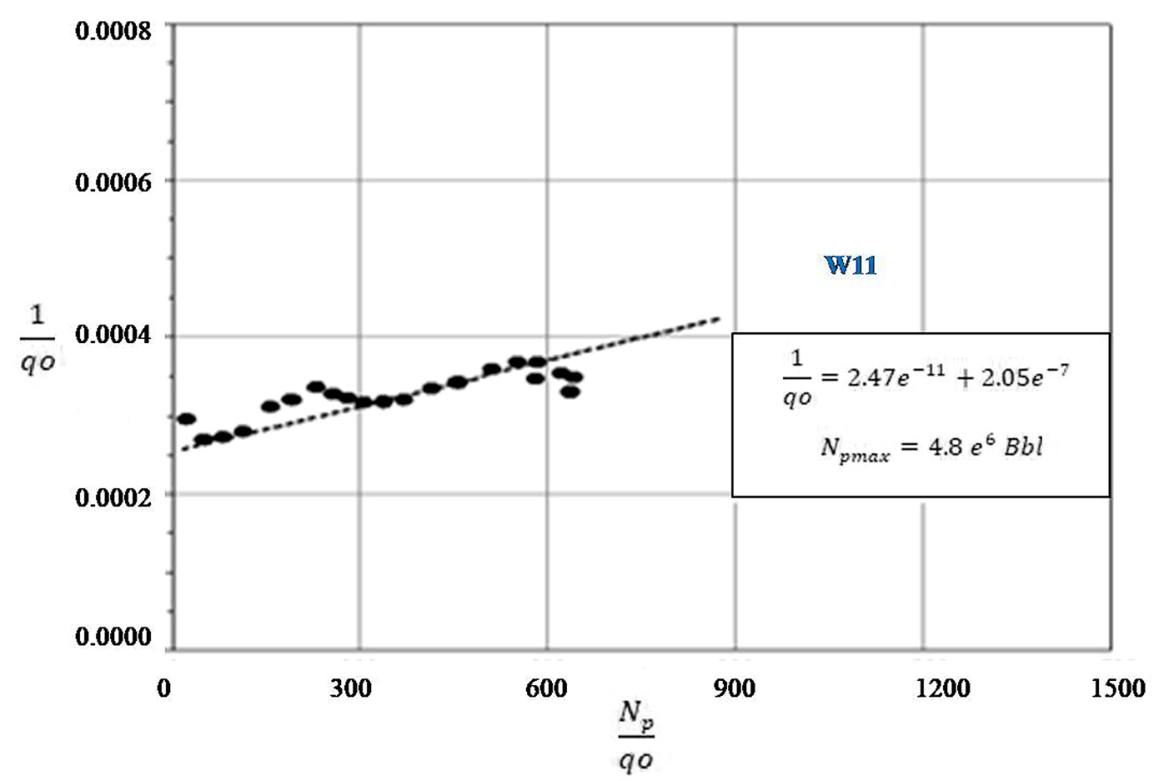

(b) 
Fig. 9 a Rate versus time DCA, b $1 / q_{o}$ versus $\mathrm{Np} / \mathrm{q}_{\mathrm{o}}$ for candidate W07

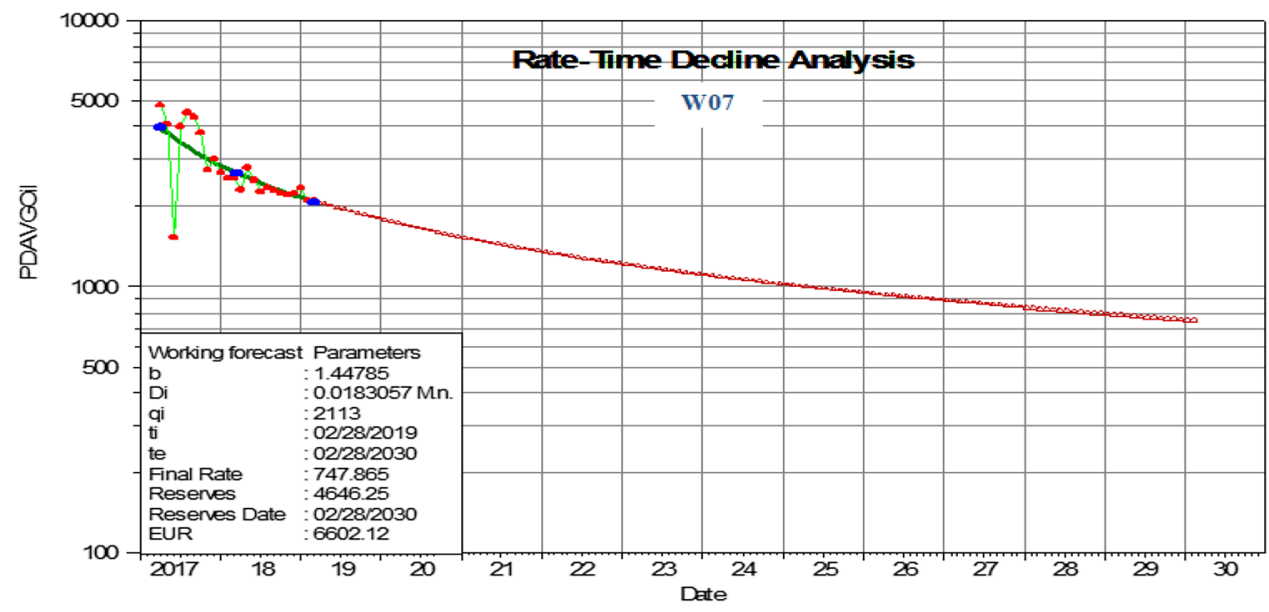

(a)

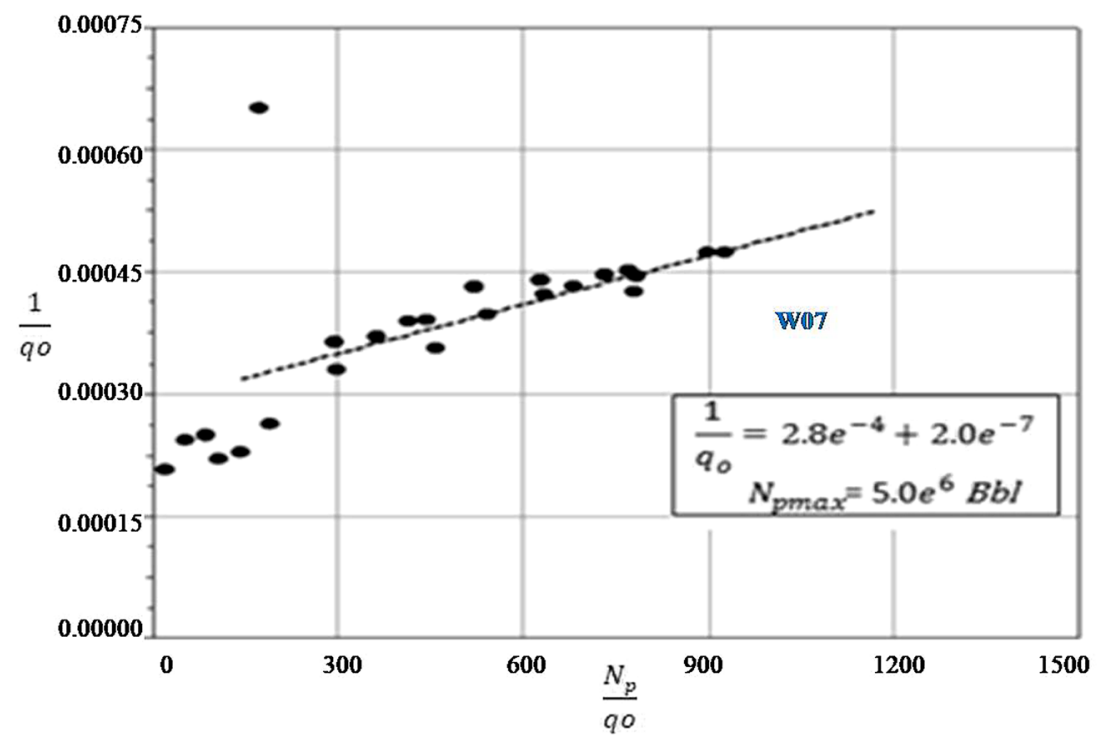

(b) 


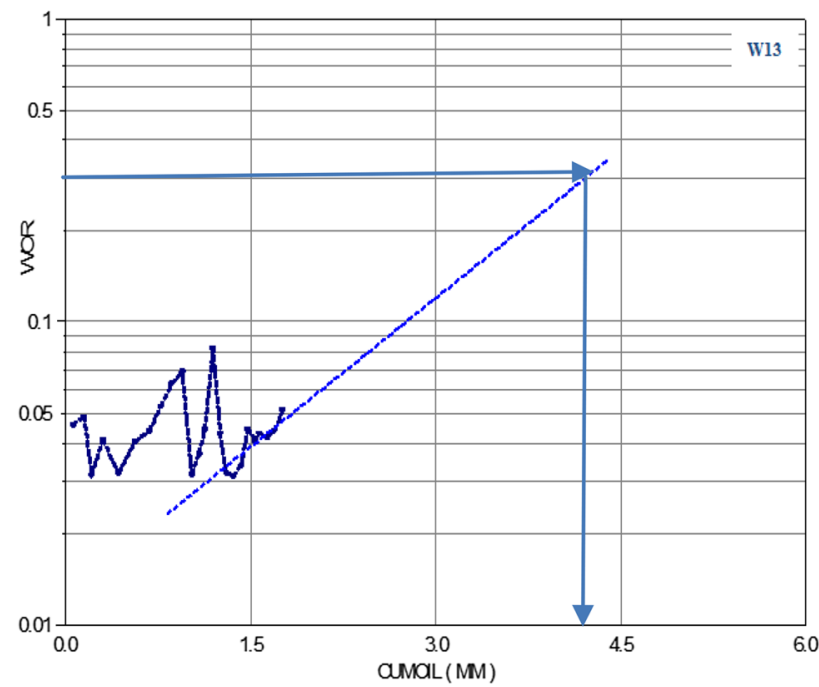

(a)

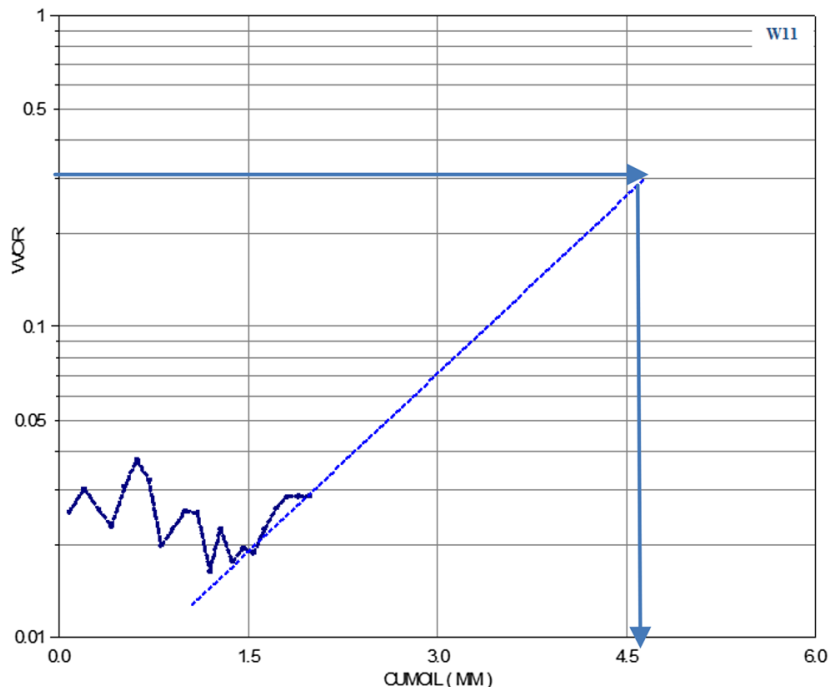

(b)

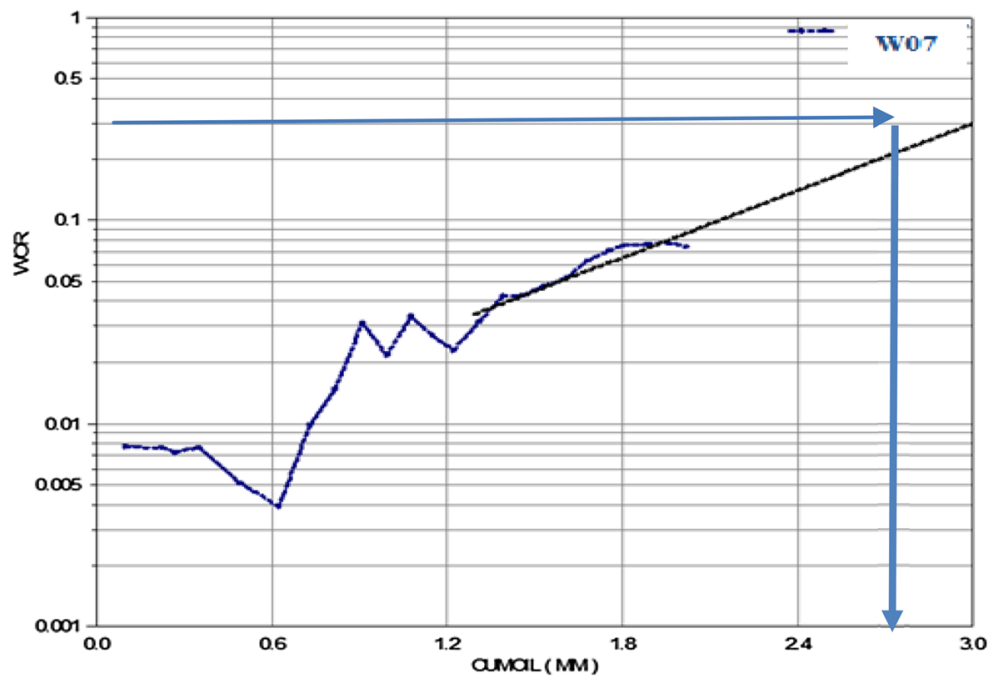

(c)

Fig. 10 Recovery plot for candidates; a W13, b W11, c W07 
Fig. 11 Recovery plot for low WOR wells a W06, b W05

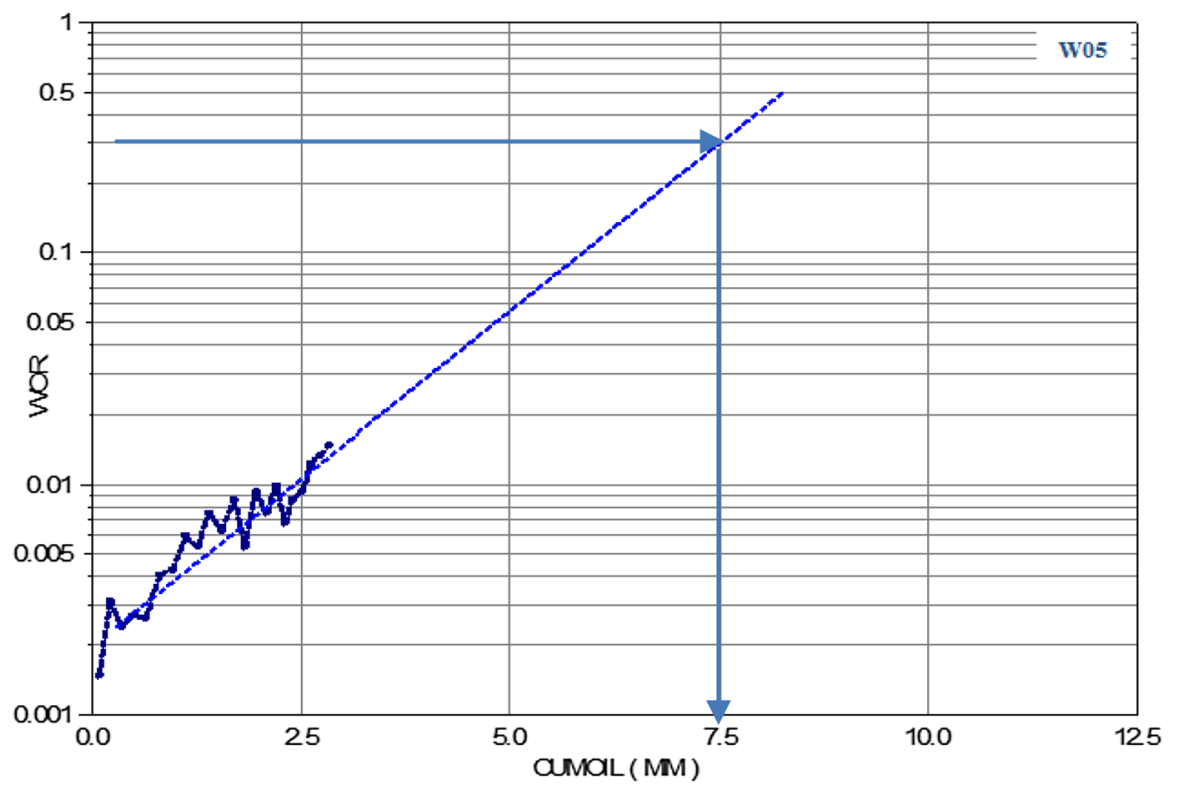

(a)

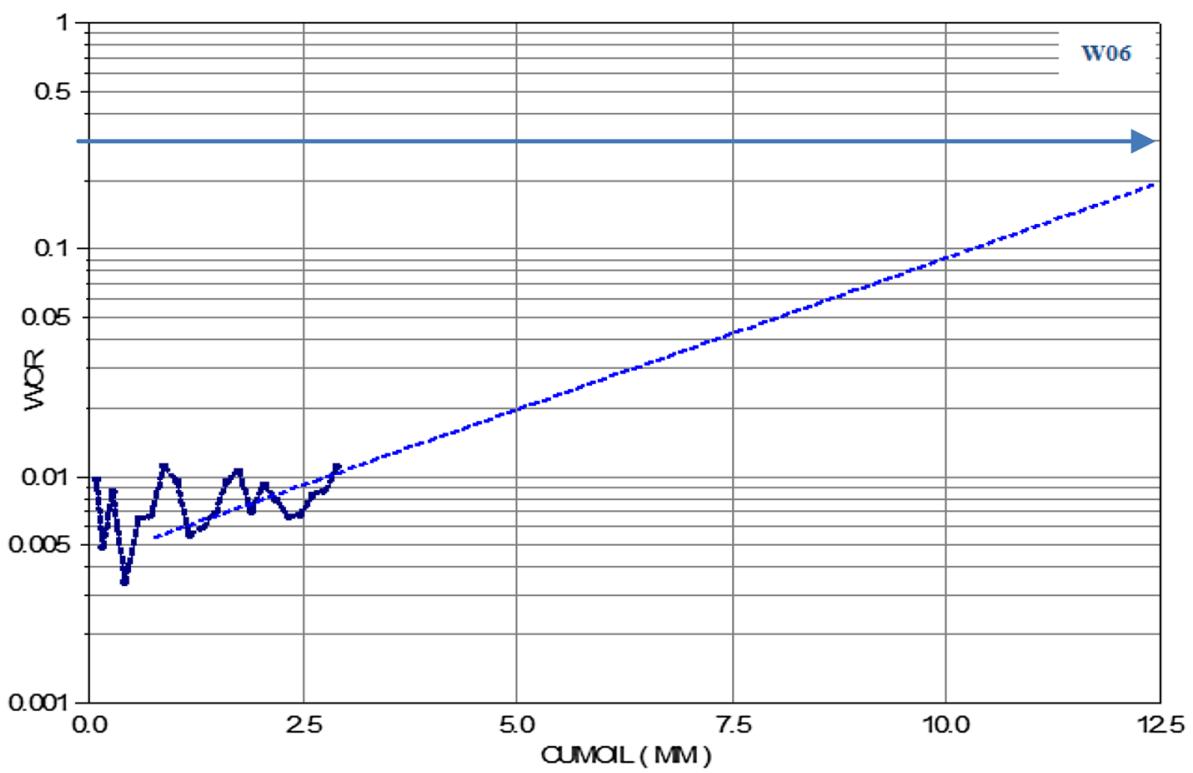

(b) 


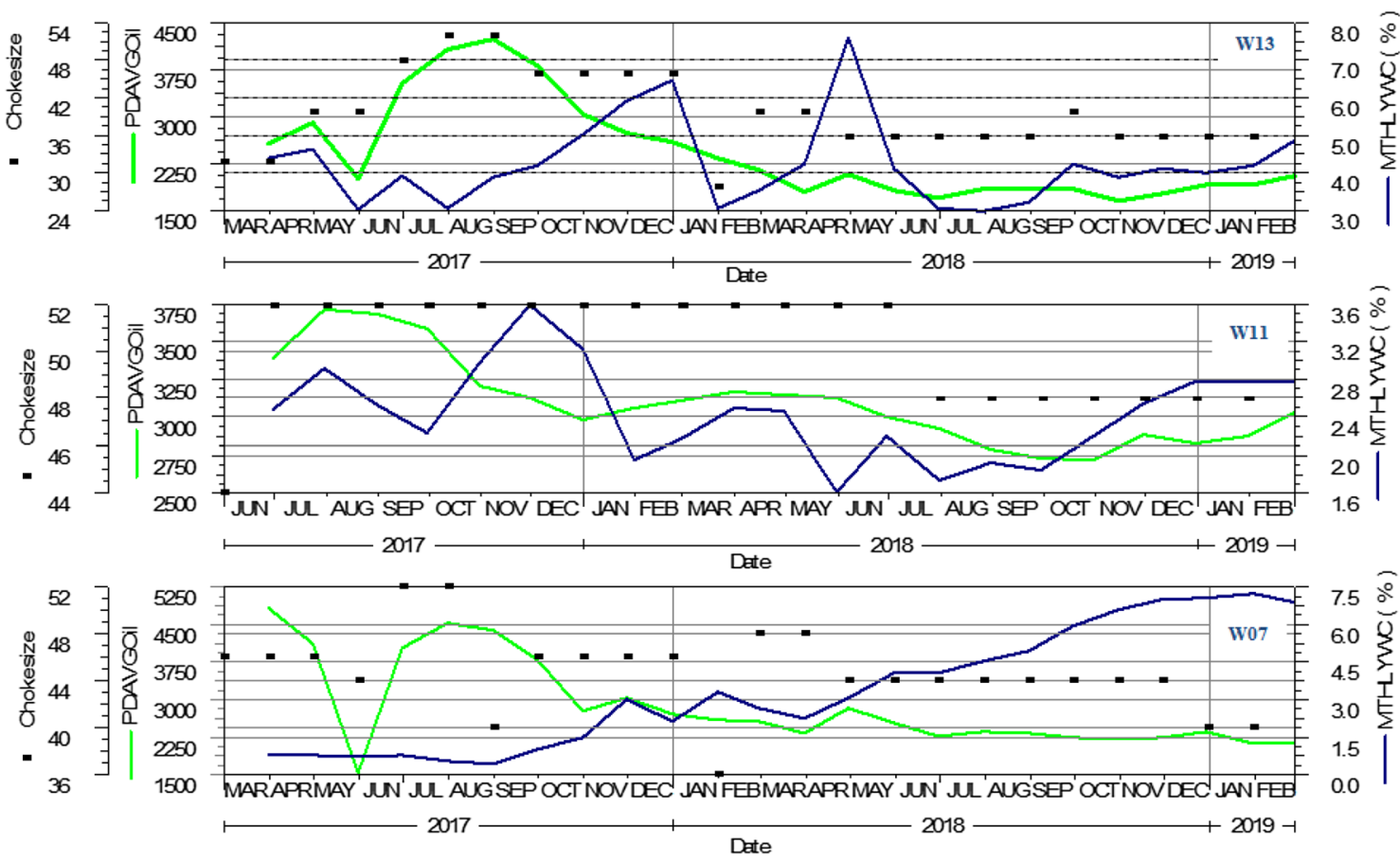

Fig. 12 Vintage plot

based on geological data, a localized water zone can be responsible for the observations in W07 candidates.

Figure 14 is the stiff diagram which compares the relative proportions of major ions in the candidate well in four different sampling times. The ion proportion scale guide is also shown as a table in Fig. 14. As can be seen in Fig. 14, sodium, potassium and chloride are predominant ions in all brine samples with almost the same proportions that confirms the source of produced water remained the same during the production history.

\section{Conclusions}

A diagnostic workflow for water shut-off candidate selection based on production data-driven analytics was proposed and implemented in OFM database platform. The water shut-off screening workflow was applied to a tight carbonate oil field, which is facing the excess water production issues at the initial stage of reservoir development. The outcome of the applied screening workflow was to identify the candidate well exposed to the critical water production. The selected well has been located in the low oil and high water production region of the heterogeneity index $(\mathrm{HI})$ plot. According to the analysis, if the proper water shut-off technique is not applied in the selected well, it will reach its WOR economic level almost at the half of its estimated production life. The observed production history suggested that the conventional method such as choke down did not help alleviate the water production issue, which is a sign of an independent water production layer source. The mechanism and source of produced water in the selected well was discussed based on diagnostics plots and a localized water coning was predicted.

Our analysis highlighted the requirement of further petrophysical and geological studies to determine the source of observed coning behavior of the candidate well. Considering the well condition that is producing from multiple layers with different permeabilities and pressures through the production lifetime, more special diagnostics for vertical communications are needed to perform to check crossflow. The special diagnostics for vertical communications can be through casing imaging testing to evaluate the quality of cement job in well and identifying flow channels behind casing, multi-rate tests to provide productivity index and average reservoir pressure of each layer and choke back tests to provide diagnostics of vertical communication through pressure differences. 


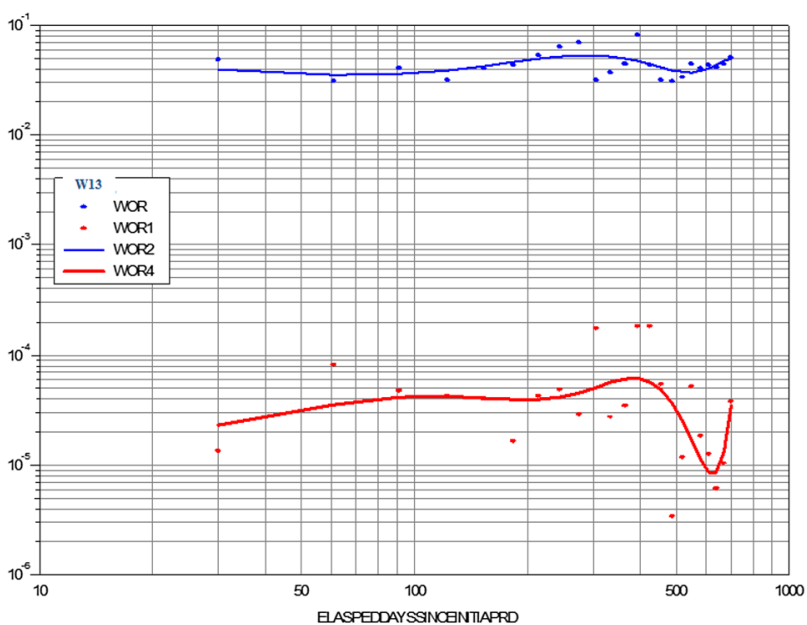

(a)

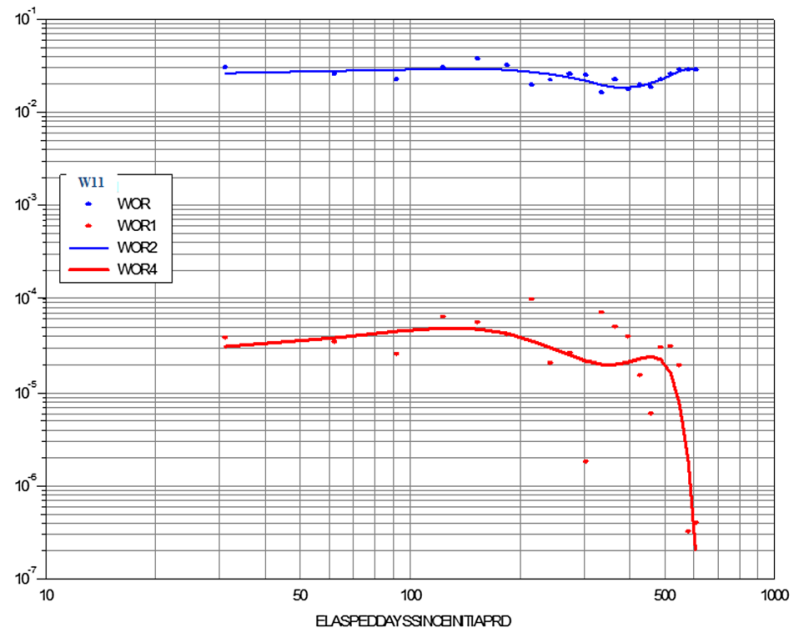

(b)

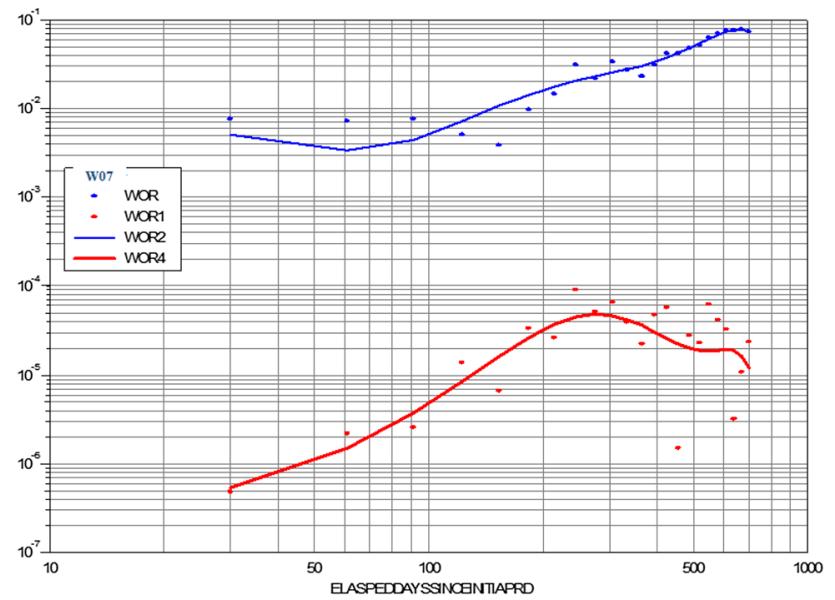

(c)

Fig. 13 Chan plots; a W13, b W11, c W07

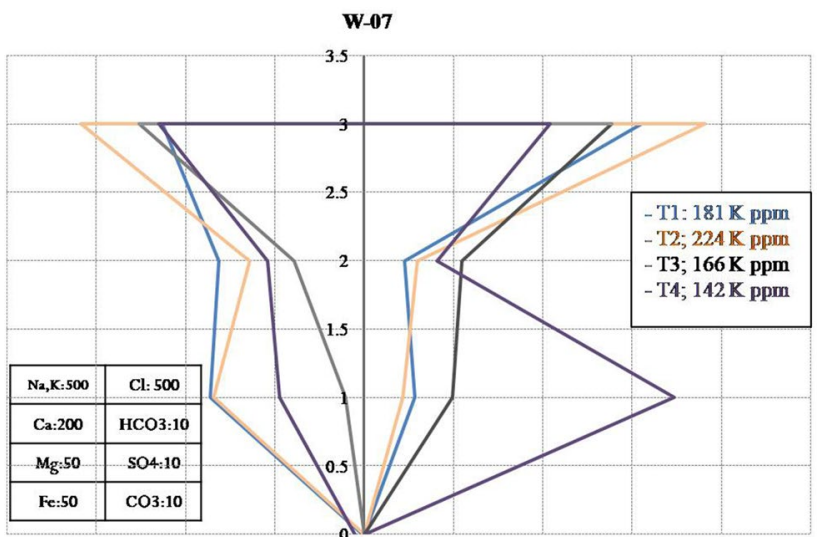

Fig. 14 W07 stiff diagram

\section{Compliance with ethical standards}

Conflict of interest The author(s) declare that they have no competing interests.

\section{References}

1. Abass E, Merghany S (2011) Integration of technical problems and diagnosis of high water cut-sudanese oil fields. J Sci Technol 13(03):137-146

2. Bavon K, Cedric P, Suhaila H, Saadi M (2012) Challenges and key learning for developing tight carbonate reservoirs. In: Abu Dhabi international petroleum conference and exhibition, 11-14 November, Abu Dhabi, UAE

3. Bill B, Mike C, Jeb T (2000) Water control. Oilfield Rev 1(30):30-51

4. Burrafato G, Pitoni E, Perez DR, Cantini S (2005) Water control in fissured reservoirs-diagnosis and implementation of solutions. Cases from North Italy. Offshore Europe. Aberdeen, United Kingdom, Society of Petroleum Engineers, p 14

5. Chan KS (1995) Water control diagnostic plots. In: SPE annual technical conference and exhibition. Society of Petroleum Engineers, Dallas, Texas, p 9

6. Evans P, Robinson K (1999) Produced water management-reservoir and facilities engineering aspects. In: Middle East oil show and conference. Society of Petroleum Engineers, Bahrain, $\mathrm{p} 6$

7. Flores JG, Elphick JJ, Lopez F, Espinel P (2008). The integrated approach to formation water management: from reservoir management to the protection of the environment. In: SPE annual technical conference and exhibition. Society of Petroleum Engineers, Denver, Colorado, USA, $\mathrm{p} 13$

8. Gaafar GR, Altunbay MM, Aziz SBA (2016) Perched-water, the concept and its effects on exploration and field development plans in sandstone and carbonate reservoirs. In: Offshore technology conference Asia. Offshore Technology Conference, Kuala Lumpur, Malaysia, p 12

9. Harami KK, Bolanos N, Sharma S, Slimani K, Abdel-Basset M, Pimentel JAR, Kiome P, Rodriguez J, Al-Ajmi MF, El Doushy A, Al Mufarrej MM (2013) Heterogeneity index and fast screening processes used in a large mature field designed for quick production gains. In: SPE Kuwait oil and gas show and conference. Society of Petroleum Engineers, Kuwait City, Kuwait, $p 15$

10. Jennings AR Jr (1991) Good wells make the best candidates for well stimulation. SPE Prod Eng 6(04):371-376 
11. Lee RS, Adamson DT, Vanderford M (2007) Visual methods for geochemical screening of possible impacts to groundwater by oilfield brines. www.semanticscholar.org

12. Zettlitzer M, Busch M (2007) Produced water and reinjection experience-zero discharge water. In: 4th international conference on produced water management, Stavanger

13. Mohd Ismail I, Che Sidik NA, Syarani Wahi F, Tan GL, Tom F, Hillis $F(2018)$ Increased oil production in super thin oil rim using the application of autonomous inflow control devices. In: SPE annual technical conference and exhibition. Society of Petroleum Engineers, Dallas, TX, USA, p 21

14. Pattnaik C, Rao NS, Al-Ashwak S, Al-Ajmi NH, Kidambi VK, Al Anzi AM, Dashti Q, Staffelbach C, Barbé J (2015) Field development and well planning in tight carbonate reservoir using fracture characterization and in-situ stress mapping from core reorientation studies: Kuwait case study. In: SPE Kuwait oil and gas show and conference. Society of Petroleum Engineers, Mishref, Kuwait, $\mathrm{p} 12$

15. Robinson K (2003) Produced water management-an integrated approach. Produced water workshop, 26th-27th March

Publisher's Note Springer Nature remains neutral with regard to jurisdictional claims in published maps and institutional affiliations. 